\title{
Late outcomes of strategic arch resection in acute type $A$ aortic dissection
}

Bo Yang, MD, PhD, ${ }^{a}$ Elizabeth L. Norton, MS, ${ }^{\mathrm{b}}$ Terry Shih, MD, ${ }^{a}$ Linda Farhat, BS, ${ }^{\mathrm{a}}$ Xiaoting Wu, PhD, Whitney E. Hornsby, PhD, ${ }^{\mathrm{c}}$ Karen M. Kim, MD, ${ }^{\mathrm{a}}$ Himanshu J. Patel, MD, ${ }^{\mathrm{a}}$ and G. Michael Deeb, $\mathrm{MD}^{\mathrm{a}}$

\section{ABSTRACT}

Objective: To compare perioperative and long-term outcomes in patients undergoing hemiarch and aggressive arch replacement for acute type A aortic dissection (ATAAD).

Methods: From 1996 to 2017, we compared outcomes of hemiarch $(\mathrm{n}=322)$ versus aggressive arch replacements (zones 2 and 3 arch replacement with implantation of 2-4 arch branches, $n=150$ ) in ATAAD. Indications for aggressive arch were arch aneurysm $>4 \mathrm{~cm}$ or intimal tear in the aortic arch that was not resectable by hemiarch replacement, or dissection of arch branches with malperfusion.

Results: Patients in the aggressive arch group were significantly younger (mean age: 57 vs 61 years old) and had significantly longer hypothermic circulatory arrest, cardiopulmonary bypass, and aortic crossclamp times. There were no significant differences in perioperative outcomes between hemiarch and aggressive arch groups, including 30-day mortality $(5.3 \%$ vs $7.3 \%, P=.38)$ and postoperative stroke rate $(7 \%$ vs $7 \%, P=.96)$. Over 15 years, Kaplan-Meier survival was similar between hemiarch and aggressive arch groups (log-rank $P=.55,10$-year survival $70 \%$ vs $72 \%$ ). Given death as a competing factor, incidence rates of reoperation over 15 years $(2.1 \%$ vs $2.0 \%$ per year, $P=1)$ and 10 -year cumulative incidence of reoperation $(14 \%$ vs $12 \%, P=.89)$ for arch and distal aorta pathology were similar between the 2 groups.

Conclusions: Both hemiarch and aggressive arch replacement are appropriate approaches for select patients with ATAAD. Aggressive arch replacement should be considered for an arch aneurysm $>4 \mathrm{~cm}$ or an intimal tear at the arch unable to be resected by hemiarch replacement, or dissection of the arch branches with malperfusion. (J Thorac Cardiovasc Surg 2019;157:1313-21)

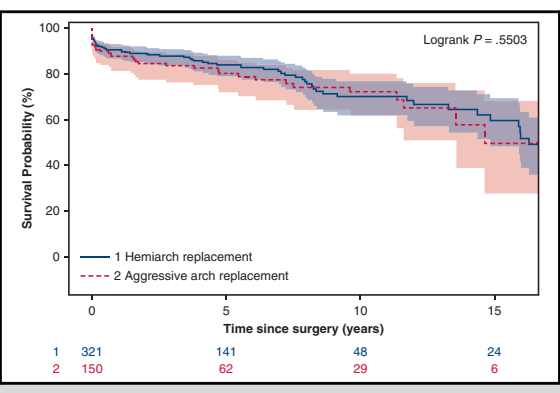

Long-term survival in hemiarch and aggressive arch replacement in patients with ATAAD.

\section{Central Message}

Both hemiarch and aggressive arch replacement are appropriate approaches for select patients with acute type A aortic dissection.

\section{Perspective}

Both hemiarch and aggressive arch replacement are appropriate approaches for select patients with acute type A aortic dissection with good short- and long-term outcomes if the procedure can achieve the goal of resecting the intimal tear at the aortic arch and/or arch aneurysm and resolve the malperfusion of arch branch vessels.

See Commentary on page 1322.
From the Departments of ${ }^{\mathrm{a}}$ Cardiac Surgery and ${ }^{\mathrm{c}}$ Internal Medicine, Michigan Medicine, Ann Arbor, Mich; and ${ }^{\mathrm{b}}$ Creighton University School of Medicine, Omaha, Neb.

Funded by the National Institutes of Health, the Phil Jenkins, David Hamilton Fund, and Darlene and Stephen J. Szatmari Fund. Dr Yang is supported by NIH K08HL130614 and R01HL141891 from the National Heart, Lung, and Blood Institute and funds from the Phil Jenkins and Darlene and Stephen J. Szatmari Fund. Dr Patel is supported by the Joe D. Morris Collegiate Professorship, the David Hamilton Fund, and the Phil Jenkins Breakthrough Fund in Cardiac Surgery.

Read at The American Association for Thoracic Surgery Aortic Symposium 2018, New York, New York, April 26-27, 2018.

Dr Yang and Ms Norton contributed equally to this article as co-first authors.

Received for publication June 19, 2018; revisions received Sept 30, 2018; accepted for publication Oct 22, 2018; available ahead of print Dec 12, 2018.

Address for reprints: Bo Yang, MD, PhD, 1500 East Medical Center Drive, 5155

Frankel Cardiovascular Center, Ann Arbor, MI 48109 (E-mail: boya@med. umich.edu).

$0022-5223 / \$ 36.00$

Copyright (C) 2018 by The American Association for Thoracic Surgery

https://doi.org/10.1016/j.jtcvs.2018.10.139
Acute type A aortic dissection (ATAAD) is a lethal event associated with an operative mortality between $20 \%$ and $25 \%{ }^{1}$ Resection of the intimal tear and replacement of the ascending aorta are considered mainstays of operative therapy. Although the aortic arch is often involved in the aortic dissection, the optimal management of the aortic arch during surgical therapy for ATAAD remains uncertain.

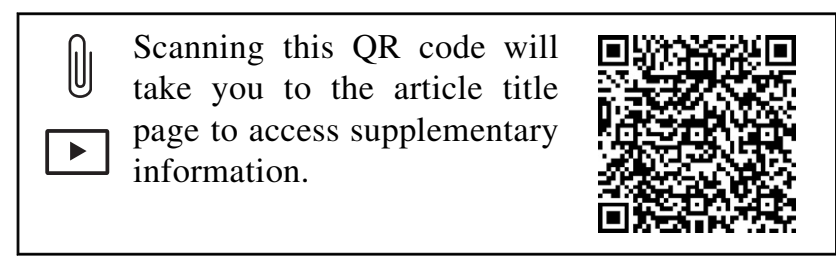




\section{Abbreviations and Acronyms \\ $\mathrm{ACP}=$ antegrade cerebral perfusion \\ ATAAD $=$ acute type A aortic dissection \\ $\mathrm{CAD}=$ coronary artery disease \\ CI = confidence interval \\ $\mathrm{HCA}=$ hypothermic circulatory arrest \\ HR = hazard ratio \\ MFS = Marfan syndrome \\ $\mathrm{RCP}=$ retrograde cerebral perfusion \\ TEVAR $=$ thoracic endovascular aortic repair}

Some surgeons advocate for a conservative approach to the aortic arch, limiting the extent of repair to a hemiarch replacement. This approach minimizes the operative time during an already-complex surgical repair, potentially lowering morbidity and mortality and sufficient to preserve life in an emergent setting. ${ }^{2-5}$ However, patients with ATAAD and hemiarch repair may be susceptible to a greater risk of aortic rupture, late stroke, and/or at an increased risk of future reoperation(s). ${ }^{6-9}$ Others advocate for a more aggressive upfront approach by addressing the long-term deterioration of the aortic arch by replacing the total arch. ${ }^{10-14}$ This approach may lead to longer circulatory arrest, crossclamp, cardiopulmonary bypass, and overall operative times, which may also increase the risk of operative mortality and/or worsened perioperative complication rates. ${ }^{15,16}$

In this context, we examined consecutive patients over the previous 20 years who underwent hemiarch versus aggressive arch replacement and compared perioperative outcomes, long-term survival, and reoperation rates. We hypothesized that with proper patient selection both hemiarch and aggressive arch replacement are appropriate operations with favorable short- and long-term outcomes.

\section{METHODS}

This study was approved (September 26, 2016; HUM00118824) by the University of Michigan Institutional Review Board (Michigan Medicine, Ann Arbor, Mich) and a waiver of consent was obtained.

\section{Study Population}

Between July 1996 and January 2017, there were a total of 545 open repairs for ATAAD; 73 were excluded from this study for (1) no arch replacement $(\mathrm{n}=32)$ and (2) zone 1 arch replacement (aortic arch was divided between innominate artery and left common carotid artery with reimplantation of innominate artery) $(n=41)$. In total, 472 patients underwent an aortic arch procedure with conservative management (hemiarch replacement, $n=322$ ) or aggressive management (zones 2/3 arch replacement, $\mathrm{n}=150$ ) during repair for an ATAAD (Figure E1). Hemiarch replacement involved replacement of the arch from the base of the innominate artery to the lesser curvature of the aortic arch with no reimplantation of arch branch vessels. Zone 2 or 3 arch replacement involved replacing the arch between the left common carotid artery and left subclavian artery or distal to the left subclavian artery with implantation of 2 to 4 arch branch vessels. Indications for aggressive arch replacement included an arch aneurysm $>4 \mathrm{~cm}$ or intimal tear located in the arch that could not be resected by a hemiarch replacement, or dissection of arch branch vessels with malperfusion.

\section{Data-Collection Techniques}

Investigators obtained Society of Thoracic Surgery data elements from the University of Michigan Department of Cardiac Surgery Data Warehouse to determine pre-, intra-, and postoperative characteristics as previously reported. ${ }^{17}$ Medical records, including operative reports, were reviewed to supplement data collection. Reoperation events included open repair (sternotomy or thoracotomy) or thoracic endovascular aortic repair (TEVAR) primarily for arch aneurysm or descending thoracic aortic aneurysm only. Reoperations primarily for aortic root pathology were included in total events of reoperation for any reason. Survival was obtained through the National Death Index database through December 31, 2015, ${ }^{18}$ supplemented with medical record review and phone call survey. Further survival data and reoperation data were collected from a thorough medical record review on patients' return visits as well as surveys (including letters and phone calls, January 2018). Loss of follow-up or end of the study period were treated as censors during the time to events analysis.

\section{Operative Techniques}

Aortic arch replacement was performed with hypothermic circulatory arrest (HCA) with or without cerebral perfusion. Retrograde cerebral perfusion (RCP) was achieved through a separate cannula in the superior vena cava. Antegrade cerebral perfusion (ACP) was achieved through direct cannulation into the innominate artery and left common carotid artery in the early years and a chimney graft sewn to the innominate artery, right axillary artery, right intrathoracic subclavian artery, or right common carotid artery in recent years. RCP, unilateral ACP, or bilateral ACP was chosen based on surgeons' preference. Conversion of unilateral ACP to bilateral ACP was initiated by inserting a separate cannula directly into the left common carotid artery when left cerebral saturation by near-infrared spectroscopy decreased independently. Arch branch vessels were resected and replaced if they were thrombosed and significantly occluded. Separate incisions were made at the neck to replace the whole common carotid arteries if the common carotid arteries were thrombosed and occluded. Arch branch vessels were replaced or reimplanted with separate branch grafts. Patients were cooled down to $<20^{\circ} \mathrm{C}$ if RCP was used and $24^{\circ} \mathrm{C}$ to $28^{\circ} \mathrm{C}$ if ACP was used in the recent years. A frozen elephant trunk (cTAG $10 \mathrm{~cm}$; Gore W. L. Gore $\&$ Associates, Flagstaff, Ariz) was placed into the true lumen of the descending thoracic aorta distal to the left subclavian artery if the intimal tear was found in the proximal descending aorta to cover the intimal tear or a very narrow true lumen was found in the distal thoracic or abdominal aorta on the computed tomography angiogram to prevent lower body malperfusion.

\section{Statistical Analysis}

Data are presented as median (interquartile range, $25 \%, 75 \%$ ) for continuous data and $\mathrm{n}(\%)$ for categorical data. Univariate comparisons between hemiarch replacement and aggressive arch replacement were performed using $\chi^{2}$ tests for categorical data and Wilcoxon rank sum tests for continuous data. Multivariable logistic regression was used to calculate the odds ratio of aggressive arch versus hemiarch replacement for 30day mortality and other postoperative major complications adjusting for age, sex, coronary artery disease (CAD), acute myocardial infarction, preoperative severe aortic insufficiency, and cardiac tamponade based on the significantly different preoperative conditions between hemiarch and aggressive arch replacement groups. Crude survival curves since operation were estimated using the nonparametric Kaplan-Meier method. Log-rank test was used to compare the survival of groups (hemiarch vs aggressive arch replacement). Cox proportional hazards regression was used to calculate the adjusted hazard ratios (HRs) with $95 \%$ confidence interval (CI) for death, also adjusting for age, sex, CAD, acute myocardial infarction, preoperative severe aortic insufficiency, and cardiac tamponade. 
TABLE 1. Demographics and preoperative characteristics of patients

\begin{tabular}{|c|c|c|c|}
\hline Variables & $\begin{array}{l}\text { Hemiarch } \\
(\mathrm{n}=\mathbf{3 2 2})\end{array}$ & $\begin{array}{c}\text { Aggressive } \\
\operatorname{arch}(\mathbf{n}=150)\end{array}$ & $\begin{array}{c}P \\
\text { value }\end{array}$ \\
\hline Patient age, y & $61(50,70)$ & $57(48,66)$ & .03 \\
\hline Sex (female) $(\%)$ & $96(30)$ & $46(31)$ & .85 \\
\hline BSA & $2.1(1.9,2.2)$ & $2.0(1.9,2.2)$ & .96 \\
\hline \multicolumn{4}{|l|}{ Pre-existing comorbidities } \\
\hline Hypertension & $230(71)$ & $107(71)$ & .98 \\
\hline Diabetes mellitus & $21(6.5)$ & $9(6)$ & .83 \\
\hline History of smoking & & & .96 \\
\hline None & $140(44)$ & $66(44)$ & \\
\hline Former & $90(28)$ & $40(27)$ & \\
\hline Current & $91(28)$ & $43(29)$ & \\
\hline $\mathrm{CAD}$ & $71(23)$ & $15(9)$ & .0004 \\
\hline COPD & $25(8)$ & $16(11)$ & .29 \\
\hline History of stroke & $9(3)$ & $3(2)$ & .76 \\
\hline History of renal failure & $12(4)$ & $6(5)$ & .885 \\
\hline On dialysis & $7(2)$ & $2(3)$ & .53 \\
\hline Marfan syndrome & $16(5)$ & $5(3)$ & .42 \\
\hline Other connective tissue disease & $3(1)$ & $2(1)$ & .65 \\
\hline PVOD & $39(12)$ & $18(12)$ & .97 \\
\hline Previous cardiac surgery & $31(10)$ & $18(12)$ & .62 \\
\hline $\begin{array}{l}\text { Aortic valve morphology } \\
\text { Unicuspid/bicuspid } \\
\text { Tricuspid } \\
\text { Quadricuspid } \\
\text { Unknown }\end{array}$ & $\begin{array}{c}34(11) \\
237(74) \\
1(0.3) \\
50(15.5)\end{array}$ & $\begin{array}{c}4(3) \\
124(83) \\
0(0) \\
22(15)\end{array}$ & .009 \\
\hline $\begin{array}{l}\text { Preoperative AI } \\
\text { None } \\
\text { Trace } \\
\text { Mild } \\
\text { Moderate } \\
\text { Severe }\end{array}$ & $\begin{array}{l}80(26) \\
39(13) \\
66(21) \\
48(16) \\
75(24)\end{array}$ & $\begin{array}{l}54(39) \\
17(12) \\
18(13) \\
21(15) \\
30(21)\end{array}$ & .055 \\
\hline Ejection fraction & $55(50,60)$ & $55(50,60)$ & .99 \\
\hline $\begin{array}{l}\text { NYHA function class } \\
\text { III/IV }\end{array}$ & $60(19)$ & $35(23)$ & .24 \\
\hline Acute myocardial infarction & $13(4)$ & $1(1)$ & .045 \\
\hline Acute stroke & $13(4)$ & $7(5)$ & .75 \\
\hline Acute renal failure & $40(12)$ & $26(17)$ & .15 \\
\hline Acute paralysis & $4(1)$ & $4(3)$ & .27 \\
\hline Cardiogenic shock & $31(10)$ & $10(7)$ & .29 \\
\hline Tamponade & $36(11)$ & $6(4)$ & .01 \\
\hline Preoperative creatinine & $1.0(0.8,1.3)$ & $1.0(0.9,1.4)$ & .61 \\
\hline \multicolumn{4}{|l|}{ Malperfusion syndrome } \\
\hline Coronary & $11(3)$ & $2(1)$ & .20 \\
\hline Cerebral & $13(4)$ & $7(5)$ & .75 \\
\hline Spinal cord & $4(1)$ & $4(3)$ & .26 \\
\hline Celiac & $7(2)$ & $1(1)$ & .24 \\
\hline Mesenteric & $27(8)$ & $16(11)$ & .42 \\
\hline Renal & $25(8)$ & $14(13)$ & .56 \\
\hline
\end{tabular}

TABLE 1. Continued

\begin{tabular}{llcc}
\hline \multicolumn{1}{c}{ Variables } & $\begin{array}{c}\text { Hemiarch } \\
(\mathbf{n = 3 2 2})\end{array}$ & $\begin{array}{c}\text { Aggressive } \\
\text { arch }(\mathbf{n}=\mathbf{1 5 0})\end{array}$ & $\begin{array}{c}\boldsymbol{P} \\
\text { value }\end{array}$ \\
\hline Extremity & $28(9)$ & $19(13)$ & .18 \\
Delayed operation & $48(15)$ & $32(21)$ & .08 \\
\hline
\end{tabular}

Data presented as median $(25 \%, 754 \%)$ for continuous data and $\mathrm{n}(\%)$ for categorical data. $B S A$, Body surface area; $C A D$, coronary artery disease; $C O P D$, chronic obstructive pulmonary disease; $P V O D$, peripheral vascular occlusive disease; $A I$, aortic insufficiency; NYHA, New York Heart Association.

As patients may experience death before reoperation, cumulative incidence curves adjusting for death as the competing risk were generated to assess reoperation rates over time. The Gray test was used to test the difference in the cumulative incidence curves between the 2 groups. Incidence rates were calculated for long-term events (such as stroke, transient ischemic attack, endocarditis, reoperation for aortic arch or descending thoracic aortic aneurysm), in which the numbers of events were divided by total patient years of follow-up. Rate ratio tests were used to compare the incidence rates between the 2 groups. Cox proportional hazards regression was used to calculate the cause-specific HRs for reoperation by treating death as a competing risk and adjusting for age, sex, hypertension, and connective tissue disease. $P$ values of less than .05 (2-tailed) were considered statistically significant. All statistical calculations used SAS 9.4 (SAS Institute, Cary, NC).

\section{RESULTS}

\section{Demographics and Preoperative Data}

Patients in the aggressive arch group were significantly younger (mean age: 57 vs 61 years old, $P=.03$ ), had significantly lower incidences of CAD, acute myocardial infarction, cardiac tamponade, and fewer bicuspid aortic valve (all $P<.05)$. Other pre-existing conditions, such as hypertension, diabetes, renal failure, chronic obstructive pulmonary disease, and New York Heart Association function class were similar between groups. There was no significant difference in malperfusion syndrome between the hemiarch and aggressive arch groups, including cerebral, spinal cord, celiac/hepatic, mesenteric, renal, and extremities malperfusion (Table 1).

\section{Intraoperative Data}

The aggressive arch group had significantly less aortic root replacements but more complex aortic arch operations with reimplantation of 2 to 4 arch branch vessels as well as significantly more frozen elephant trunk placements, use of ACP, and longer HCA, cardiopulmonary bypass, and aortic crossclamp times. The lowest temperature of the body during HCA was similar between the 2 groups. There were no significant differences between groups for concomitant surgeries (including coronary artery bypass, mitral valve, and tricuspid valve surgery) or intraoperative transfusion of packed red blood cells (Table 2).

\section{Perioperative Outcomes}

There were no significant differences in perioperative outcomes between hemiarch and aggressive arch groups, 
TABLE 2. Intraoperative outcomes

\begin{tabular}{|c|c|c|c|}
\hline Variables & $\begin{array}{l}\text { Hemiarch } \\
(\mathbf{n}=322)\end{array}$ & $\begin{array}{c}\text { Aggressive } \\
\operatorname{arch}(n=150)\end{array}$ & $\begin{array}{c}P \\
\text { value }\end{array}$ \\
\hline \multicolumn{4}{|l|}{ Aortic root procedure } \\
\hline AVR only & $5(2)$ & $3(2)$ & .71 \\
\hline Root replacement & $117(36)$ & $28(19)$ & $<.0001$ \\
\hline Bentall & 37 (11.5) & $15(10)$ & \\
\hline Inclusion & $53(16.5)$ & $6(4)$ & \\
\hline VSARR & $27(8)$ & $7(5)$ & \\
\hline Root repair & $178(55)$ & $98(65)$ & .04 \\
\hline Frozen elephant trunk & $11(3)$ & $18(12)$ & .0003 \\
\hline $\mathrm{CPB}$ time, $\min$ & $217.5(176,269)$ & $227(190,274)$ & .056 \\
\hline Crossclamp time, min & $144(108,195)$ & $160(133,205)$ & .002 \\
\hline \multicolumn{4}{|l|}{$\mathrm{HCA}$} \\
\hline HCA time, min & $32(26,39)$ & $43.5(34,55)$ & $<.0001$ \\
\hline $\mathrm{ACP}$ or $\mathrm{RCP}$ & & & $<.0001$ \\
\hline $\mathrm{ACP}$ & $91(28)$ & $54(36)$ & \\
\hline $\mathrm{RCP}$ & $194(60)$ & $5(3)$ & \\
\hline Both ACP and RCP & $32(10)$ & $91(61)$ & \\
\hline Neither & $5(2)$ & $0(0)$ & \\
\hline Lowest temperature, ${ }^{\circ} \mathrm{C}$ & $18(16.7,19.8)$ & $18(16.2,22)$ & .46 \\
\hline Bladder & $24.5(19.5,31.9)$ & $26(19.7,29.6)$ & .90 \\
\hline Esophageal & $22.6(17.6,31.2)$ & $24.2(18.6,29.9)$ & .47 \\
\hline \multicolumn{4}{|l|}{ Concomitant procedures } \\
\hline $\mathrm{CABG}$ & $20(6)$ & $6(4)$ & .33 \\
\hline Mitral valve & $0(0)$ & $2(1)$ & .1 \\
\hline Tricuspid valve & $4(1)$ & $0(0)$ & .31 \\
\hline $\begin{array}{l}\text { Blood transfusions } \\
\qquad \text { (PRBCs) }\end{array}$ & & & .39 \\
\hline 0 units & $63(21)$ & $25(17)$ & \\
\hline 1 unit & $25(8)$ & 7 (5) & \\
\hline 2 units & $26(9)$ & $14(10)$ & \\
\hline$\geq 3$ units & $189(62)$ & $100(68.5)$ & \\
\hline
\end{tabular}

Data presented as median $(25 \%, 75 \%)$ for continuous data and $\mathrm{n}(\%)$ for categorical data. AVR, Aortic valve replacement; VSARR, valve-sparing aortic root replacement; $C P B$, cardiopulmonary bypass; $H C A$, hypothermic circulatory arrest; $A C P$, antegrade cerebral perfusion; $R C P$, retrograde cerebral perfusion; $C A B G$, coronary artery bypass graft; $P R B C s$, packed red blood cells.

including postoperative myocardial infarction, stroke and paraplegia, new-onset renal failure, new hemodialysis, permanent dialysis, sepsis, prolonged ventilation, reoperation for bleeding, length of hospital stay, 30-day mortality (5.3\% vs $7.3 \%, P=.38$ ), in-hospital mortality (Table 3 ), and operative mortality, which included mortality occurring within 30 days postoperatively and/or in-hospital (7\% vs $9 \%, P=.41)$. The multivariable logistic regression showed that only reoperation for bleeding was significantly greater in the aggressive arch replacement group with adjusted odds ratio of $1.97(P=.049)$, and the 30-day mortality and other major complications were not significantly different (Table 4).

\section{Long-Term Outcomes}

From all 472 patients, we had $356(75.4 \%)$ patients' responses to the surveys and information in the medical charts. Our total follow-up time for long-term events was 2524.5 patient years. The mean follow-up time was 5.3 years. Sixty percent $(285 / 472)$ of all cases were performed in the second decade (2008-2017).

The long-term survival was similar between hemiarch and aggressive arch groups: 10-year Kaplan-Meier survival: $70 \%(95 \% \mathrm{CI}, 62 \%-77 \%)$ versus $72 \%(95 \% \mathrm{CI}$, $62 \%-80 \%$ ), Log-rank test $P$ value $=.55$ (Figure 1). After adjustment for age, sex, CAD, acute myocardial infarction, preoperative severe aortic insufficiency, and cardiac tamponade in the Cox proportional hazard regression, there was no statistically significant difference in late mortality between aggressive arch and hemiarch groups ( $\mathrm{HR}_{\text {adjusted, }}$ 1.4; $95 \% \mathrm{CI}, 0.92-2.2, P=.11)$. The adjusted HR of allcause death for age was $1.033(95 \%$ CI, 1.02-1.05, $P=.0003)$, for CAD was $1.7(95 \% \mathrm{CI}, 1.09-2.7$, $P=.02)$, and for acute myocardial infarction was 2.2 (95\% CI, 0.9-5.8, $P=.1)$.

The incidence rates of combined reoperations for the aortic arch and descending thoracic or thoracoabdominal aortic pathology were not significantly different in hemiarch versus aggressive arch groups, including open repair through sternotomy for aortic arch pathology and thoracotomy or TEVAR for descending thoracic or thoracoabdominal aortic aneurysm. Incidence rates of reoperation for separate aortic arch pathology and descending thoracic aortic aneurysm or thoracoabdominal aneurysm were not significantly different between groups, either (Table 5). Ten-year postoperative cumulative incidence of reoperation primarily for the pathology of the aortic arch, descending, or thoracoabdominal aorta was not significantly different between hemiarch and aggressive arch groups adjusted for death as a competing factor $(13.9 \%$; $95 \%$ CI, 9.2\%$19.7 \%$ vs $11.7 \%$; $95 \%$ CI, $6.7 \%-18.2 \%$ ); Gray test $P$ value $=.89$, Figure $2, A$ ), nor the cumulative incidence of all reoperation for any aortic pathology, including aortic root, ascending aorta, arch, and distal aorta (Figure 2, B). Given death as the competing event, hemiarch replacement compared with aggressive arch replacement did not significantly increase the hazard of reoperation for aortic arch pathology or descending thoracic or thoracoabdominal aortic pathology (hemiarch replacement vs aggressive arch replacement, $\mathrm{HR}_{\text {adjusted }}, 1.08 ; \quad 95 \%$ CI, $0.58-1.9$; $P=.81$ ). The 30 -day mortality was $0 \%$ for both subsequent open thoracic or thoracoabdominal aortic aneurysm repair and TEVAR (Table E1).

\section{DISCUSSION}

In this study, we report our 20-year experience of managing aortic arch replacement in 472 patients with ATAAD. We found with proper patient selection, the 30-day mortality and perioperative stroke rate were similarly low in both hemiarch and aggressive arch replacement groups. The 10 -year survival was greater than $70 \%$ in both groups 
TABLE 3. Postoperative outcomes

\begin{tabular}{|c|c|c|c|}
\hline Variables & $\begin{array}{l}\text { Hemiarch } \\
(n=322)\end{array}$ & $\begin{array}{l}\text { Aggressive } \\
\text { arch } \\
(n=150)\end{array}$ & $\begin{array}{c}P \\
\text { value }\end{array}$ \\
\hline Myocardial infarction & $4(1)$ & $1(1)$ & 1 \\
\hline Cerebrovascular accident & $24(7)$ & $11(7)$ & .96 \\
\hline Atrial fibrillation & $126(39)$ & $45(30)$ & .055 \\
\hline Pneumonia & $65(20)$ & $23(15)$ & .21 \\
\hline New-onset renal failure & $31(10)$ & $15(10)$ & .90 \\
\hline On dialysis & $14(4)$ & $7(5)$ & .88 \\
\hline Permanent & $4(1)$ & $4(3)$ & .27 \\
\hline Reoperation for bleeding & $26(8)$ & $18(12)$ & .17 \\
\hline Deep sternal wound infection & $8(2.5)$ & $5(3)$ & .56 \\
\hline Sepsis & $11(3)$ & $2(1)$ & .24 \\
\hline Paraplegia & $3(1)$ & $1(1)$ & .77 \\
\hline GI complications & $29(9)$ & $11(7)$ & .54 \\
\hline Need for tracheostomy & $13(4)$ & $4(3)$ & .46 \\
\hline Prolonged vent & $179(56)$ & $84(56)$ & .93 \\
\hline Hours intubated & $44(23.9,106.5)$ & $50(24,100.5)$ & .9 \\
\hline Reintubation & $19(6)$ & $13(9)$ & .27 \\
\hline Postop length of stay, $d$ & $10(7,17)$ & $11(7,18)$ & .5 \\
\hline Total length of stay, d & $12(7,19)$ & $12(8,22)$ & .6 \\
\hline Intraoperative mortality & $2(1)$ & $3(2)$ & .33 \\
\hline In-hospital mortality & $22(7)$ & $14(9)$ & .34 \\
\hline 30-d mortality & $17(5)$ & $11(7)$ & .38 \\
\hline
\end{tabular}

Data presented as median $(25 \%, 75 \%)$ for continuous data and $\mathrm{n}(\%)$ for categorical data. GI, Gastrointestinal. GI complications include but are not limited to: GI bleeding, pancreatitis, cholecystitis, mesenteric ischemia, hepatic failure, prolonged ileus, and clostridium difficile.

with no significant difference in the reoperation rate for pathology of the aortic arch and distal aorta over the 15-year follow-up period (Video 1).

How much of the dissected aortic arch should be replaced in ATAAD? Our criteria for zone 2 or 3 aortic arch replacement includes an arch aneurysm $>4 \mathrm{~cm}$ or intimal tear located in the arch, which cannot be resected by a hemiarch replacement, or dissection of the arch branch vessels with malperfusion. Our primary goal is not to leave any intimal tear or aneurysm in the aortic arch and resolve malperfusion of arch branch vessels. If hemiarch replacement cannot achieve this goal, we replace the arch as much as needed. Although zone 2/3 arch replacements are more complex than hemiarch replacements as shown in our study (Table 2), the perioperative outcomes and long-term survival were similar to the patients in the hemiarch group. This finding is consistent with reports from studies using data from the International Registry of Aortic Dissection, ${ }^{19}$ German Registry for Acute Aortic Dissection type $\mathrm{A},{ }^{20}$ and a meta-analysis, ${ }^{11}$ although the in-hospital mortality or 30-mortality in those studies was higher (mortality for hemiarch: $13 \%-20 \%$, mortality for total arch: 17\%-26\%).

The operative mortality was much lower than that reported in the Society of Thoracic Surgeons Database, International Registry of Aortic Dissection, and German Registry for Acute Aortic Dissection type A probably due to 2 factors: (1) Case selection: we manage the patients with malperfusion syndrome (end-organ necrosis and dysfunction) with endovascular fenestration and stenting first, then perform open aortic repair if patients recover from organ failure. ${ }^{21}$ In the past decade, we treated 354 patients with ATAAD with $(n=49)$ or without $(n=305)$ endovascular amenable malperfusion syndrome with this strategy. After malperfusion was resolved by endovascular fenestration/stenting, 15 (4\%) patients died in the hospital all due to organ failure resulted from malperfusion syndrome but not aortic rupture before open aortic repair. ${ }^{21}$ With this strategy, our in-hospital mortality of all comers with or without open aortic repair was $11 \%$ in the past decade. $^{21}$ Most patients with malperfusion syndrome (necrotic bowel or limb) are treated medically as nonoperative candidates at many institutions and are often not included in the reported operative mortality. (2) All ATAAD cases were primarily performed by 3 aortic surgeons who perform 15 to 25 ATAAD cases/year. Our case volume of ATAAD has increased every year in the past 2 decades to 50 to 60 cases/year (Figure E2). All of the ATAAD cases are concentrated on by 3 aortic surgeons. Every aortic

TABLE 4. Logistic model for 30-day mortality and perioperative outcomes

\begin{tabular}{|c|c|c|c|c|}
\hline Outcomes & $\begin{array}{c}\text { Crude OR }(95 \% \text { CI }) \\
\text { aggressive vs hemiarch }\end{array}$ & $P$ value & $\begin{array}{c}\text { Adjusted } * \text { OR }(95 \% \text { CI }) \\
\text { aggressive vs hemiarch }\end{array}$ & $P$ value \\
\hline 30-d mortality & $1.37(0.62,2.99)$ & .44 & $1.94(0.84,4.51)$ & .12 \\
\hline Myocardial infarction & $0.53(0.06,4.82)$ & .58 & $0.71(0.07,7.16)$ & .77 \\
\hline Stroke & $0.94(0.45,1.97)$ & .87 & $1.06(0.50,2.29)$ & .87 \\
\hline New-onset renal failure & $0.97(0.50,1.88)$ & .92 & $1.14(0.58,2.24)$ & .70 \\
\hline Prolonged ventilation & $1.48(0.88,2.47)$ & .14 & $1.68(0.96,2.93)$ & .07 \\
\hline Reoperation for bleeding & $1.55(0.82,2.93)$ & .17 & $1.97(1.001,3.87)$ & .049 \\
\hline Hospital length of stay & $1.11(0.74,1.67)$ & .61 & $1.35(0.88,2.08)$ & .17 \\
\hline
\end{tabular}

$O R$, Odds ratio; $C I$, confidence interval. *Adjusted for age, sex, severe aortic insufficiency, coronary artery disease, acute myocardial infarction, tamponade. 


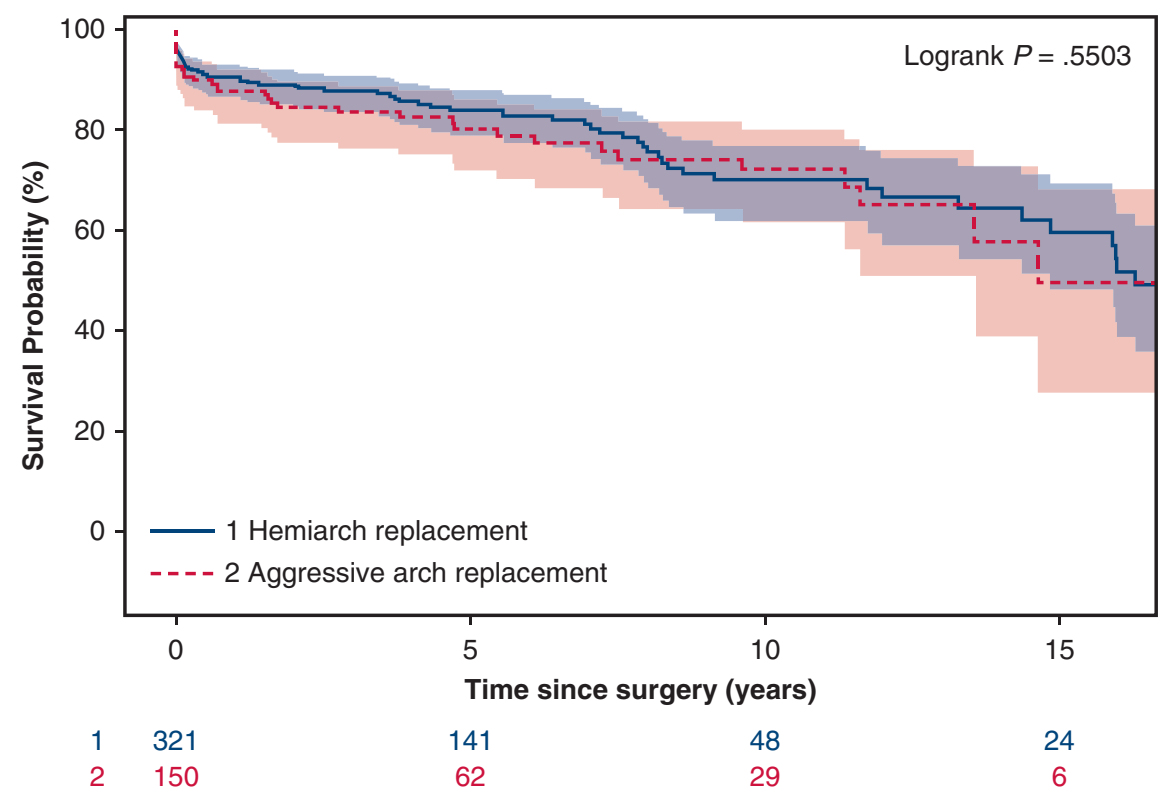

FIGURE 1. Kaplan-Meier long-term survival of patients with acute type A aortic dissection undergoing hemiarch or aggressive arch replacement.

surgeon is very familiar with procedures of the aortic root, arch, frozen elephant trunk, and malperfusion management in patients with ATAAD. This focused practice has helped us achieve better outcomes, as also seen in other institutions. ${ }^{22}$ We think that the management of the aortic dissection patient should be restricted to surgeons with skill and interest in the management of aortic disease rather than leaving the aortic "disaster" in the hands of the juniorlevel surgeon on call unsupervised.

The second goal of arch replacement in ATAAD is to resolve the malperfusion of arch branch vessels. If there is dissection of arch branch vessels with significant occlusion, blood pressure gradient $(>15 \mathrm{~mm} \mathrm{Hg}$ ) between aorta and radial arteries, or stroke, we replace the arch branches via aggressive arch replacement to resolve malperfusion and hopefully prevent future stroke from the embolization of the thrombus in the dissected common carotid arteries. We do not compromise the arch surgery because of a difficult aortic root replacement. We also perform endovascular fenestration and stenting before open aortic repair to resolve malperfusion in patients with ATAAD complicated by malperfusion syndrome. ${ }^{21}$ Relieving the concern of malperfusion and end-organ death during the open aortic repair allows us to do a more aggressive operation if needed. The hemiarch group had more root procedures likely because they had more root pathology (such as root aneurysm) but less arch pathology (such as arch aneurysm).

TABLE 5. Complications and reoperations for pathology of aortic arch and distal aorta during long-term follow-up

\begin{tabular}{|c|c|c|c|c|c|}
\hline & \multicolumn{2}{|r|}{ Hemiarch } & \multicolumn{2}{|c|}{ Aggressive arch } & \multirow[b]{2}{*}{$P$ value } \\
\hline & $\mathrm{n}=322$ & Incidence rate $(\% /$ year $)$ & $\mathbf{n}=\mathbf{1 5 0}$ & Incidence rate $(\% /$ year $)$ & \\
\hline TIA & 3 & 0.17 & 1 & 0.12 & 1 \\
\hline Stroke & 6 & 0.35 & 2 & 0.25 & 1 \\
\hline Bleeding & 1 & 0.06 & 3 & 0.38 & .19 \\
\hline \multicolumn{6}{|l|}{ Reoperation primarily for } \\
\hline Aortic arch aneurysm & 7 & 0.43 & 0 & 0 & .15 \\
\hline TAA/A & 27 & 1.7 & 15 & 2.0 & .62 \\
\hline \multicolumn{6}{|l|}{ Surgery type } \\
\hline TEVAR & 4 & 0.25 & 2 & 0.27 & 1 \\
\hline Open TAA/A repair & 23 & 1.4 & 13 & 1.8 & 41 \\
\hline Open arch repair (median sternotomy) & 7 & 0.43 & 0 & 0 & .15 \\
\hline Total procedures & 34 & 2.1 & 15 & 2.0 & 1 \\
\hline
\end{tabular}

$P$ value indicates the difference of the incidence rate between the hemiarch and aggressive arch groups. TIA, Transient ischemic attack; TAA/A, thoracic aortic aneurysm (TAA) or thoracoabdominal aortic aneurysm (TAAA); TEVAR, thoracic endovascular aortic repair. 

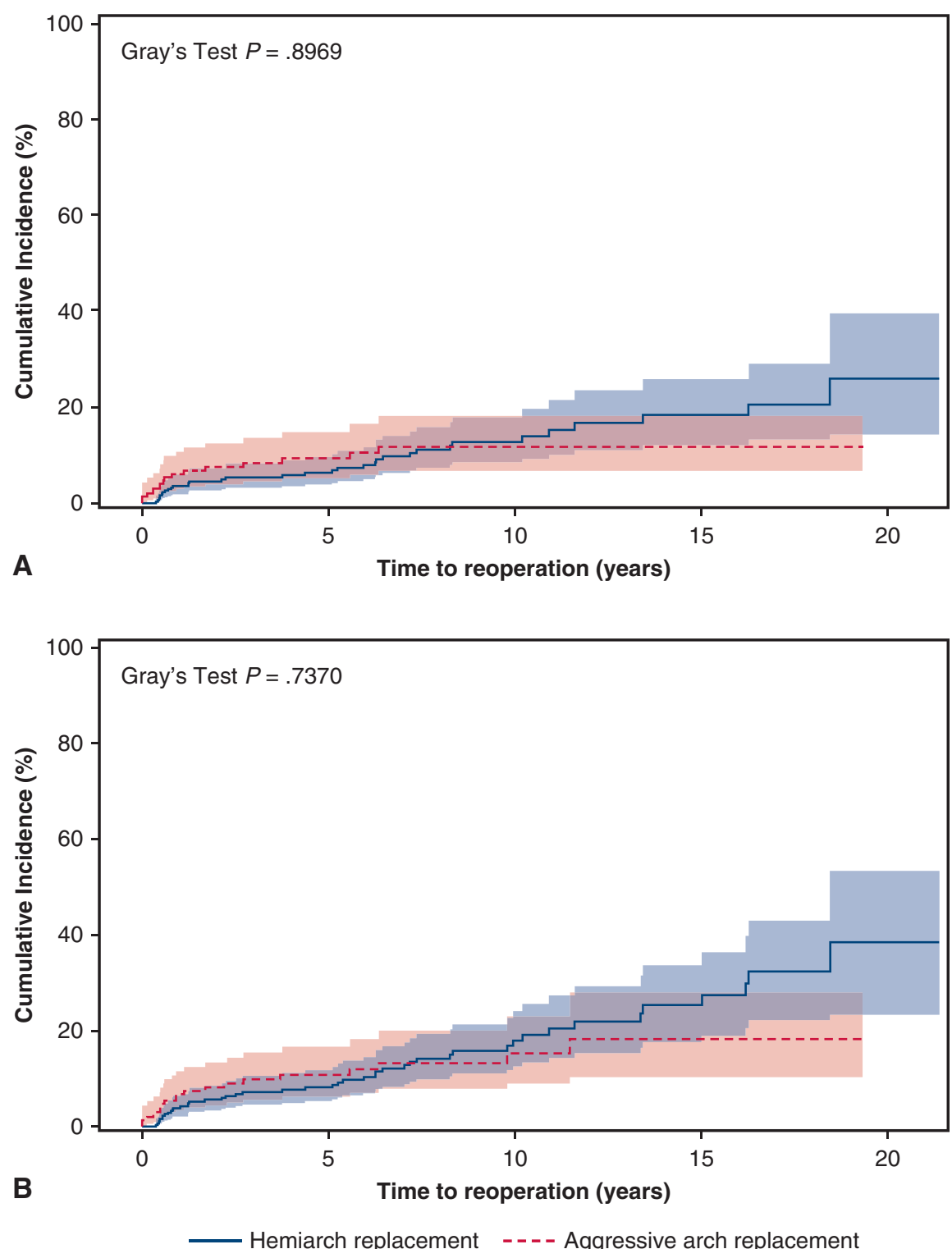

FIGURE 2. A, The cumulative incidence of only reoperation for aortic arch and distal aorta, including sternotomy for arch pathology, open repair of descending thoracic or thoracoabdominal aortic aneurysm, and thoracic endovascular aortic repair, adjusting for death as the competing event. B, The cumulative incidence of all reoperation for any aortic pathology, including aortic root, ascending aorta, arch, and distal aorta, adjusting for death as the competing event.

Our perioperative stroke rate in the aggressive arch replacement group was similar to those in other large studies. ${ }^{12,19,20}$ In recent years, the stroke rate was $4 \%,{ }^{17}$ which is similar to the results reported by the Pittsburgh group (stroke rate $3.4 \%$ ) in the same time frame, who replace all the dissected carotid arteries with or without malperfusion. ${ }^{23}$ In our study, the incidence of transient ischemic attack and stroke in patients with ATAAD with total arch replacement during follow-up was $0.12 \%$ and $0.25 \%$ separately (Table 4 ). Therefore, we recommend replacing the arch branches if they are dissected with subsequent malperfusion to achieve low perioperative and long-term stroke rates. Taken together, our results suggest that aggressive arch replacement can be performed in patients with ATAAD with good outcomes despite the complexity of the operation.

Should we perform aggressive arch for all patients with ATAAD? The answer is no. If the patient does not have an arch aneurysm, intimal tear at the arch, or malperfusion of the brain or upper extremity, we recommend performing a hemiarch replacement. Currently in our practice, we have also found that the proximal arch aneurysm or intimal tear can frequently be resected with an aggressive hemiarch replacement by a peninsular technique ${ }^{17}$ replacing $60 \%$ 


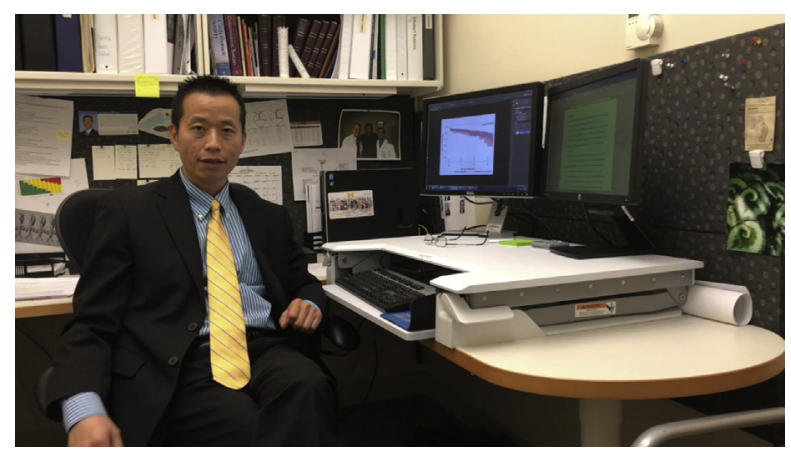

VIDEO 1. Discussion of aortic arch management in acute type A aortic dissection repair. Video available at: https://www.jtcvs.org/article/S00225223(18)32936-2/fulltext.

to $70 \%$ of the dissected aortic arch to achieve our primary goal. In this study, $68 \%$ of dissected arches were repaired with a hemiarch replacement. In the past decade, we have performed more hemiarch replacements than zone $2 / 3$ arch replacements every year (Figure E2). The criteria of aggressive arch replacement have not changed over the past couple decades. Compared with the aggressive arch group, the patients with a hemiarch replacement had similar perioperative outcomes (Table 3), long-term survival rate (Figure 1), as well as reoperation rate for pathology of the aortic arch, descending thoracic aorta, or thoracoabdominal aorta in the 15-year follow-up (Figure 2). This result highlights that hemiarch replacement was adequate for the dissected aortic arch in patients with ATAAD if there was no aortic arch aneurysm or intimal tear left at the aortic arch. Shi and colleagues ${ }^{3}$ reported similar results to those reported herein such as no difference in short- and longterm outcomes by comparing the hemiarch and total arch replacement with frozen elephant trunk in patients with ATAAD with no intimal tear at the arch. Zhang and colleagues ${ }^{24}$ did a similar study and found that the hemiarch with frozen elephant trunk had a greater reintervention rate due to multiple intimal tears at the arch after the repair of the ATAAD, including intimal tears at the distal anastomotic site at the arch. Their results support the concept and importance of not leaving or creating any intimal tear at the dissected aortic arch after arch repair, which is our primary goal.

The management of the aortic arch in patients with connective tissue disease in the setting of ATAAD is still controversial. Bachet and colleagues ${ }^{25}$ recommend an aggressive approach to the arch in patients with Marfan syndrome (MFS) with ATAAD to prevent potential reoperation of the arch; however, they only had 19 patients with MFS with ATAAD in their study. Schoenhoff and colleagues ${ }^{26}$ emphasized, in their study, the need for reinterventions is precipitated by the dissection itself and not by limiting the procedure to the hemi-arch replacement in patients with acute aortic dissection. We did not use known connective tissue disease as an indication for total arch replacement. After ATAAD, patients with MFS frequently develop an aneurysm of the distal aorta, including descending thoracic or thoracoabdominal aortic aneurysm, which warrants an operation. Total arch replacement does not eliminate the need for reoperation of a distal aortic aneurysm. The distal arch aneurysm in patients with MFS that can develop after ATAAD repair can be repaired during descending thoracic or thoracoabdominal aortic aneurysm repair. The Cox proportional hazard analysis of cumulative incidence of reoperation showed the HR of MFS versus non-MFS was 1.15 (95\% CI, 0.53, 2.50), $P=.72$. Our data did not support connective tissue disease as an indication for an aggressive approach of arch replacement.

In the real world, total arch replacement in patients with ATAAD still remains a challenge as operative mortality of total arch replacement in patients with ATAAD ranges from $17 \%$ to $33 \% .^{12,16,19,20,27-29}$ Some studies ${ }^{16,29}$ recommend conservative arch management for all patients with ATAAD because it is reasonable to conservatively manage the aortic arch in ATAAD to save the patient's life first, especially if the surgeon is inexperienced with ATAAD and/or total arch replacement. At our center, patients with ATAAD are operated on by aortic surgeons familiar with aortic pathology and arch replacement. We also manage the malperfusion of abdominal viscera and extremities upfront with endovascular fenestration and stenting and then perform the open aortic repair following resolution of malperfusion. Resolving the malperfusion preoperatively allows us to be more aggressive during the aortic arch repair in patients with ATAAD if indicated, as we described previously.

Our study is limited by a single-center and retrospective experience. The incomplete follow-up of patients could underestimate the incidence of reoperations in both groups. Most patients who had ATAAD repair at the University of Michigan came back for additional operations if they needed one. We suspect those who were lost to follow-up are more likely not to have had a reoperation or died without notice. However, we cannot exclude the possibility that some reoperations could have been performed at other places and patients were lost to follow-up. The number of patients with follow-up at 15 years postoperative was relatively small, but there is a reasonably good sample size at 10-year follow-up. Primarily only aortic surgeons operate on ATAAD, and we manage malperfusion syndrome endovascularly before the open aortic repair. Therefore, our experience may not apply to all centers operating on patients with ATAAD.

\section{CONCLUSIONS}

Both hemiarch and aggressive arch replacements are appropriate operations for select patients with ATAAD with good short- and long-term outcomes. Patients with 
ATAAD should have aggressive arch replacement to resect the aortic arch aneurysm or intimal tear in the arch that cannot be resected by hemiarch replacement, or replace the arch branch vessels to resolve malperfusion of dissected aortic arch branch vessels.

\section{Conflict of Interest Statement}

Authors have nothing to disclose with regard to commercial support.

\section{References}

1. Berretta P, Patel HJ, Gleason TG, Sundt TM, Myrmel T, Desai N, et al. IRAD experience on surgical type A acute dissection patients: results and predictors of mortality. Ann Cardiothorac Surg. 2016;5:346-51.

2. Ohtsubo S, Itoh T, Takarabe K, Rikitake K, Furukawa K, Suda H, et al. Surgical results of hemiarch replacement for acute type A dissection. Ann Thorac Surg. 2002;74:S1853-6; discussion S1857-63.

3. Shi E, Gu T, Yu Y, Yu L, Wang C, Fang Q, et al. Early and midterm outcomes of hemiarch replacement combined with stented elephant trunk in the management of acute DeBakey type I aortic dissection: comparison with total arch replacement. J Thorac Cardiovasc Surg. 2014;148:2125-31.

4. Shiono M, Hata M, Sezai A, Niino T, Yagi S, Negishi N. Validity of a limited ascending and hemiarch replacement for acute type A aortic dissection. Ann Thorac Surg. 2006;82:1665-9.

5. Westaby S, Saito S, Katsumata T. Acute type A dissection: conservative methods provide consistently low mortality. Ann Thorac Surg. 2002;73:707-13.

6. Heo W, Song SW, Lee KH, Lee SY, Kim TH, Baek MY, et al. Surgery for acute Type I aortic dissection without resection of supra-aortic entry sites leads to unfavourable aortic remodelling. Eur J Cardiothorac Surg. 2018; 54:34-41.

7. Kirsch M, Legras A, Bruzzi M, Louis N. Fate of the distal aorta after surgical repair of acute DeBakey type I aortic dissection: a review. Arch Cardiovasc Dis. 2011;104:125-30.

8. Rylski B, Hahn N, Beyersdorf F, Kondov S, Wolkewitz M, Blanke P, et al. Fate of the dissected aortic arch after ascending replacement in type A aortic dissection. Eur J Cardiothorac Surg. 2017:51:1127-34.

9. Zierer A, Voeller RK, Hill KE, Kouchoukos NT, Damiano RJ Jr, Moon MR. Aortic enlargement and late reoperation after repair of acute type A aortic dissection. Ann Thorac Surg. 2007;84:479-86; discussion 486-7.

10. Li B, Ma WG, Liu YM, Sun LZ. Is extended arch replacement justified for acute type A aortic dissection? Interact Cardiovasc Thorac Surg. 2015;20: $120-6$.

11. Poon SS, Theologou T, Harrington D, Kuduvalli M, Oo A, Field M. Hemiarch versus total aortic arch replacement in acute type A dissection: a systematic review and meta-analysis. Ann Cardiothorac Surg. 2016;5:156-73.

12. Rice RD, Sandhu HK, Leake SS, Afifi RO, Azizzadeh A, Charlton-Ouw KM, et al. Is total arch replacement associated with worse outcomes during repair of acute type A aortic dissection? Ann Thorac Surg. 2015;100:2159-65; discussion 2165-6.

13. Smith HN, Boodhwani M, Ouzounian M, Saczkowski R, Gregory AJ, Herget EJ, et al. Classification and outcomes of extended arch repair for acute Type A aortic dissection: a systematic review and meta-analysis. Interact Cardiovasc Thorac Surg. 2017;24:450-9.
14. Sun L, Qi R, Zhu J, Liu Y, Zheng J. Total arch replacement combined with stented elephant trunk implantation: a new "standard" therapy for type a dissection involving repair of the aortic arch? Circulation. 2011;123:971-8.

15. Kim JB, Chung CH, Moon DH, Ha GJ, Lee TY, Jung SH, et al. Total arch repair versus hemiarch repair in the management of acute DeBakey type I aortic dissection. Eur J Cardiothorac Surg. 2011;40:881-7.

16. Lio A, Nicolo F, Bovio E, Serrao A, Zeitani J, Scafuri A, et al. Total arch versus hemiarch replacement for type A acute aortic dissection: a single-center experience. Tex Heart Inst J. 2016;43:488-95.

17. Yang B, DeBenedictus C, Watt T, Farley S, Salita A, Hornsby W, et al. The impact of concomitant pulmonary hypertension on early and late outcomes following surgery for mitral stenosis. J Thorac Cardiovasc Surg. 2016;152: 394-400 e391.

18. Centers for Disease Control and Prevention; National Center for Health Statistics. National death index. Available at: https://www.cdc.gov/nchs/ndi/index. htm. Accessed December 27, 2017.

19. Larsen M, Trimarchi S, Patel HJ, Di Eusanio M, Greason KL, Peterson MD, et al Extended versus limited arch replacement in acute Type A aortic dissection. Eur J Cardiothorac Surg. 2017;52:1104-10.

20. Easo J, Weigang E, Holzl PP, Horst M, Hoffmann I, Blettner M, et al. Influence of operative strategy for the aortic arch in DeBakey type I aortic dissection: analysis of the German registry for acute aortic dissection Type A. J Thorac Cardiovasc Surg. 2012;144:617-23.

21. Yang B, Rosati CM, Norton EL, Kim KM, Khaja MS, Dasika N, et al. Endovascular fenestration/stenting first followed by delayed open aortic repair for acute type A aortic dissection with malperfusion syndrome. Circulation. 2018;138:2091-103.

22. Andersen ND, Benrashid E, Ross AK, Pickett LC, Smith PK, Daneshmand MA, et al. The utility of the aortic dissection team: outcomes and insights after a decade of experience. Ann Cardiothorac Surg. 2016;5:194-201.

23. Trivedi D, Navid F, Balzer JR, Joshi R, Lacomis JM, Jovin TG, et al Aggressive aortic arch and carotid replacement strategy for type A aortic dissection improves neurologic outcomes. Ann Thorac Surg. 2016;101: 896-903; discussion 903-905.

24. Zhang H, Lang X, Lu F, Song Z, Wang J, Han L, et al. Acute type A dissection without intimal tear in arch: proximal or extensive repair? J Thorac Cardiovasc Surg. 2014;147:1251-5.

25. Bachet J, Larrazet F, Goudot B, Dreyfus G, Folliguet T, Laborde F, et al. When should the aortic arch be replaced in Marfan patients? Ann Thorac Surg. 2007;83: S774-9; discussion S785-90.

26. Schoenhoff FS, Kadner A, Czerny M, Jungi S, Meszaros K, Schmidli J, et al Should aortic arch replacement be performed during initial surgery for aortic root aneurysm in patients with Marfan syndrome? Eur J Cardiothorac Surg. 2013;44:346-51; discussion 351.

27. Di Eusanio M, Berretta P, Cefarelli M, Jacopo A, Murana G, Castrovinci S, et al Total arch replacement versus more conservative management in type A acute aortic dissection. Ann Thorac Surg. 2015;100:88-94.

28. Hawkins RB, Downs EA, Johnston LE, Mehaffey JH, Fonner CE, Ghanta RK et al. Impact of transcatheter technology on surgical aortic valve replacement volume, outcomes, and cost. Ann Thorac Surg. 2017;103:1815-23.

29. Rylski B, Branchetti E, Bavaria JE, Vallabhajosyula P, Szeto WY, Milewski RK, et al. Modeling of predissection aortic size in acute type A dissection: more than $90 \%$ fail to meet the guidelines for elective ascending replacement. $J$ Thorac Cardiovasc Surg. 2014;148:944-948 e941.

Key Words: aortic dissection, aortic arch surgery, total arch replacement, long-term outcome, acute type A aortic dissection 


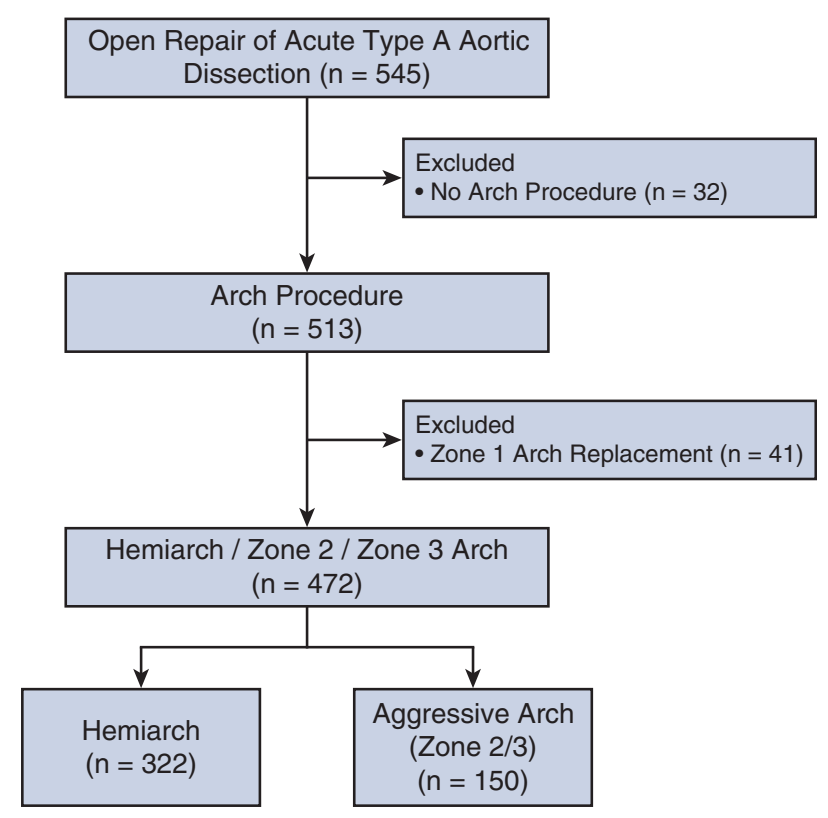

FIGURE E1. Study selection among the total of 545 patients undergoing central aortic repair for an acute type A aortic dissection at the University of Michigan from July 1996 to January 2017.

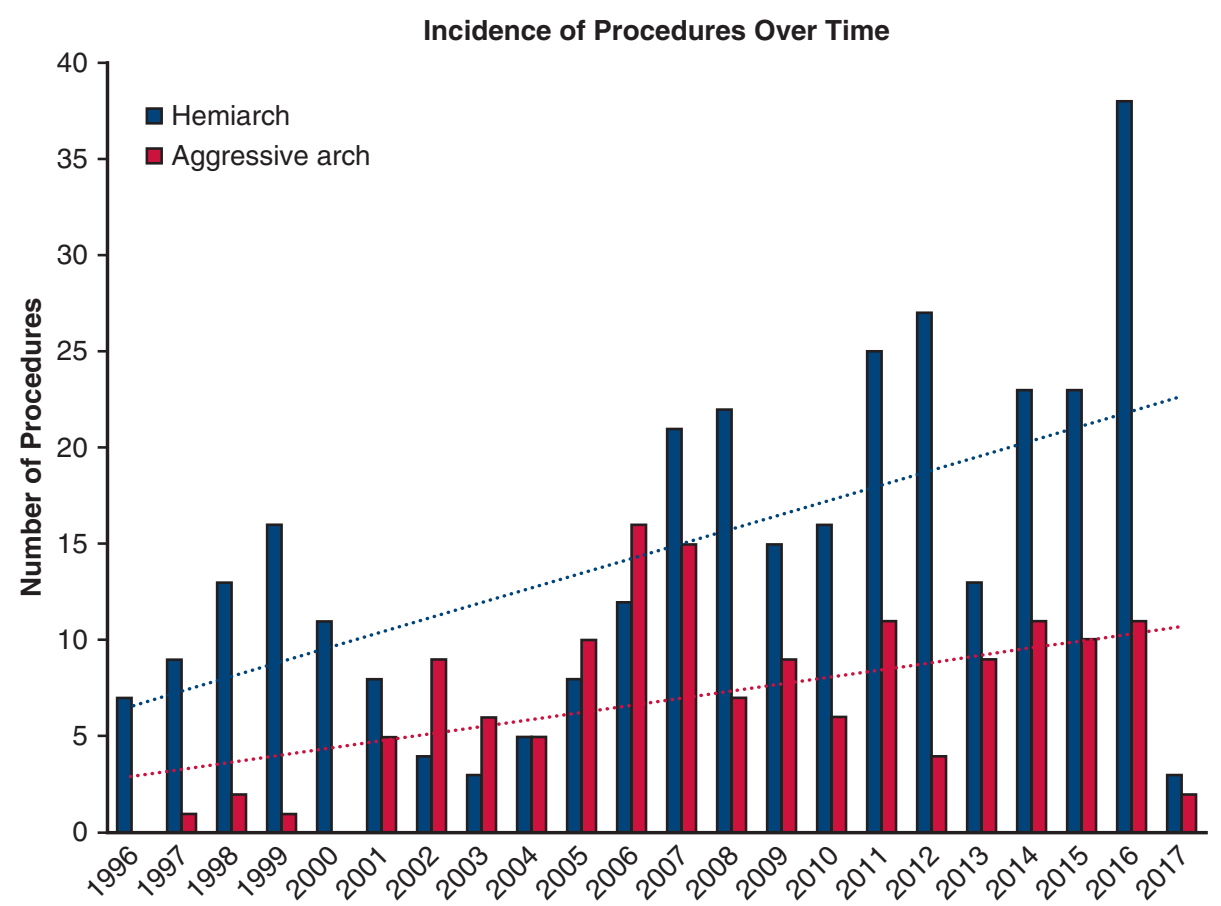

FIGURE E2. Annual number of the hemiarch and aggressive arch replacements in acute type A aortic dissection over time. 1996 only includes July to December. 2017 only includes January. 
TABLE E1. Open TAA/A and TEVAR first redo surgery outcomes

\begin{tabular}{llll}
\hline \multicolumn{1}{c}{ Variables } & $\begin{array}{c}\text { TEVAR } \\
(\mathbf{n = 6})\end{array}$ & $\begin{array}{c}\text { Open TAA/A } \\
(\mathbf{n}=\mathbf{3 6})\end{array}$ & $\boldsymbol{P}$ value \\
\hline Patient age, y & $66(62,78)$ & $59(52,64)$ & .015 \\
\hline Sex (female) $(\%)$ & $3(50)$ & $7(19.4)$ & .134 \\
\hline Myocardial infarction & $0(0)$ & $0(0)$ & \\
\hline Cerebrovascular accident & $0(0)$ & $3(8.3)$ & 1.0 \\
\hline Atrial fibrillation & $0(0)$ & $5(13.9)$ & 1.0 \\
\hline Pneumonia & $0(0)$ & $1(2.8)$ & 1.0 \\
\hline New-onset renal failure & $0(0)$ & $0(0)$ & \\
\hline Reoperation for bleeding & $0(0)$ & $0(0)$ & \\
\hline Deep sternal wound infection & $0(0)$ & $0(0)$ & \\
\hline Sepsis & $0(0)$ & $0(0)$ & \\
\hline Paraplegia & $0(0)$ & $1(2.8)$ & 1.0 \\
\hline GI complications & $0(0)$ & $2(5.6)$ & 1.0 \\
\hline Need for tracheostomy & $0(0)$ & $0(0)$ & \\
\hline Prolonged vent & $0(0)$ & $0(0)$ & \\
\hline Reintubation & $0(0)$ & $0(0)$ & \\
\hline Intraoperative mortality & $0(0)$ & $0(0)$ & 1.0 \\
\hline In-hospital mortality & $0(0)$ & $1(2.8)$ & \\
\hline 30-d mortality & $0(0)$ & $0(0)$ & \\
\hline Dat & & \\
\hline
\end{tabular}

Data presented as median $(25 \%, 75 \%)$ for continuous data and $\mathrm{n}(\%)$ for categorical data. TEVAR, Thoracic endovascular aortic repair; TAA/A, thoracic aortic aneurysm (TAA) or thoracoabdominal aortic aneurysm (TAAA); GI, gastrointestinal. 